\title{
Fruiting Body Production and Aroma Profile Analysis of Agrocybe aegerita Cultivated on Different Substrates
}

\author{
Vanessa Kleofas, Laura Sommer, Marco A. Fraatz, Holger Zorn, Martin Rühl* \\ Institute of Food Chemistry and Food Biotechnology, Justus Liebig University Giessen, Giessen, Germany \\ Email: ${ }^{*}$ martin.ruehl@Icb.chemie.uni-giessen.de
}

Received 20 February 2014; revised 24 March 2014; accepted 5 April 2014

Copyright (C) 2014 by authors and Scientific Research Publishing Inc.

This work is licensed under the Creative Commons Attribution International License (CC BY). http://creativecommons.org/licenses/by/4.0/

c) (i) Open Access

\section{Abstract}

The industrial cultivated basidiomycete Agrocybe aegerita, also known as "Pioppino" in Italy or "Samthaube" in Germany, is a high quality mushroom with a delicious aroma. Cultivation of A. aegerita on wheat straw supplemented with different residues of the food industry showed the highest yields in fruiting body production with a biological efficiency of $36 \%$ when black tea pomace was added. The addition of other substrates resulted in biological efficiencies of $23 \%$ to $33 \%$. Besides the mushroom yields, the number and size of fruiting bodies harvested on the different substrates were determined. A comparison of the aroma profiles of $A$. aegerita grown on wheat straw and on wheat straw supplemented with black tea by means of GC/MS/MS/0 is presented.

\section{Keywords}

Agrocybe aegerita, Aroma Profile, Mushroom Production, GC/MS/MS/0

\section{Introduction}

Since thousands of years, mushrooms are favoured due to their delicious taste and their nutritive and healthy values [1] [2]. The most commonly cultivated mushrooms are Agaricus bisporus, Pleurotus ostreatus and Lentinula edodes counting for more than $80 \%$ of the worldwide mushroom production [1]. Besides, several other tasty mushrooms can be cultivated and have attracted increasing interest in recent years. One of them, the black poplar mushroom A. aegerita (syn. A. cylindracea) is a well-known high quality mushroom with a pleasant aroma [3]. The fruiting bodies of $A$. aegerita are known for biosynthesis of several secondary metabolites that have been studied in more detail regarding antioxidative and antimicrobial activity [4] as well as tumor pro-

"Corresponding author. 
tective capacities [5].

In general, the quality of mushrooms depends essentially on the aroma of the fruiting bodies. The aroma profile varies between species and may be influenced by the culture conditions or by addition of aroma precursors like unsaturated fatty acids [6] [7]. Furthermore, cooking modifies the aroma profile and causes the formation of new volatiles [8]. Among the different volatile compounds, mushrooms form a series of C8-compounds of which oct-1-en-3-ol is the most abundant one [6].

Growth of A. aegerita on lignocellulosic material, such as wheat straw, cotton waste, sawdust, corn cobs and peanut shells has been reported [8]-[11]. Additionally, many other lignocellulosic waste materials have been suggested for edible mushroom cultivation [12], but have not been used for A. aegerita so far. Compared to $L$. edodes and $P$. ostreatus the cultivation yields of $A$. aegerita are typically low [3] and the productivity of the commercial strains decreases after consecutive cultivation rounds [13]. Besides the optimal cultivation conditions, the choice of the production strain is an important factor for the yields.

In the European Union each year nearly 90 million tons of food waste is produced and 38\% directly accrues at the food industry [14]. In the current study, the utilisation of residual materials from the food industry was tested for the production of fruiting bodies of $A$. aegerita. The spent substrates may be further used after mushroom production as animal feed, because degradation of lignocelluloses by mushrooms improves the availability of nutrients [15].

\section{Materials and Methods}

\subsection{Cultivation of Agrocybe aegerita}

Mushroom spawn of A. aegerita (strain 4022) was provided by Sylvan Inc. (Horst, The Netherlands). The spawn was stored at $4^{\circ} \mathrm{C}$ until inoculation.

For cultivation of $A$. aegerita wheat straw supplemented with different residual materials from the food industry was used. A. aegerita was cultivated on $100 \%$ wheat straw, $100 \%$ cocoa shells and on wheat straw supplemented with either cocoa shells (17\%), citrus pellets $(17 \%)$, carrot mesh $(17 \%)$ or black tea pomace (17\% and $45 \%$ ). The humidity of the different substrates was determined by an infrared moisture analyser (MA 35, Sartorius, Göttingen, Germany) at $105^{\circ} \mathrm{C}$. The dry weights of these substrates were used to calculate the amount of water to adjust the humidity of the non-dried substrates to $75 \%$. The substrates were mixed in a cement mixer (GBM 125, DEMA, Übrigshausen, Germany). Autoclavable polyethylene culture bags (Unicorn Imp. \& Mfg. Corp., Culemborg, Netherlands) were filled with $1.5 \mathrm{~kg}$ of the moistened substrate. For sterilisation, the bags were autoclaved at $121^{\circ} \mathrm{C}$ for $1 \mathrm{~h}$. After the substrate was cooled down, the bags were inoculated with $10 \%(\mathrm{w} / \mathrm{w})$ A. aegerita spawn. All substrates were produced in four replications. For mycelia growth, the bags were incubated at $24^{\circ} \mathrm{C}$ in darkness at $75 \%$ relative air humidity for four weeks in a climate chamber (Vötsch VB 1514, Minicon, Balingen-Frommern, Germany) until the mycelium was grown through the whole substrate.

For induction of fructification, the bags were sliced (width $1 \mathrm{~cm}$ ) at six positions, and the culture conditions were modified to $90 \%$ relative humidity, $20^{\circ} \mathrm{C}$, and incandescent light (400 lux) for $12 \mathrm{~h}$ in the climate chamber. The fruiting bodies were harvested when the caps were arcuate down and the lamellas were still not visible. The biological efficiency (BE) was calculated as percentage yield of fresh fruiting bodies of A. aegerita in relation to dry weight of the substrate.

$$
\mathrm{BE} \%=\frac{\text { Weight of fresh fruiting bodies }}{\text { Weight of dry substrate }} \times 100 \%
$$

\subsection{Extraction}

Chemicals were provided by Carl Roth (Karlsruhe, Germany), Sigma-Aldrich (Steinheim, Germany), Acros Organics (Geel, Belgium) and Fisher Scientific (Schwerte, Germany). Solvents were distilled before use. Ripe fruiting bodies were harvested and frozen at $-20^{\circ} \mathrm{C}$. $100 \mathrm{~mL}$ methanol, $100 \mathrm{~mL}$ water and $1 \mathrm{~mL}$ hept-1-en-3-ol solution (5.0833 $\mathrm{mg} \cdot \mathrm{L}^{-1}$ in ethanol or $5.2025 \mathrm{mg} \cdot \mathrm{L}^{-1}$ in methanol) as internal standard were added to $100 \mathrm{~g}$ fruiting bodies. The sample was homogenised with a masher (HR1361/00, Philips, Hamburg, Germany) and an Ultra-Turrax (T 25, IKA, Staufen, Germany). After centrifugation $\left(4700 \times g, 4^{\circ} \mathrm{C}, 10 \mathrm{~min}\right)$, the supernatant was subjected to liquid/liquid extraction (three times with $200 \mathrm{~mL}$ pentane/diethyl ether, 1:1.12 v/v) in a separatory 
funnel. The combined pentane/diethyl ether fractions were dried over anhydrous sodium sulphate and concentrated to a volume of about $1 \mathrm{~mL}$ using a Vigreux column (water bath temperature $45^{\circ} \mathrm{C}$ ).

\subsection{GC/MS/MS/O Analysis}

The analyses were performed by means of a gas chromatograph (7890A, Agilent Technologies, Waldbronn, Germany) equipped with a VF-WAXms column (Agilent Technologies, $30 \mathrm{~m} \times 0.25 \mathrm{~mm}$ i.d., $0.25 \mu \mathrm{m}$ film thickness), operated in splitless mode (splitless time $0.5 \mathrm{~min}$ ). Inlet temperature was $250^{\circ} \mathrm{C}$. Helium (5.0) was used as carrier gas at $1.56 \mathrm{~mL} \cdot \mathrm{min}^{-1}$ (constant flow). The oven temperature program was set to: $40^{\circ} \mathrm{C}(3 \mathrm{~min}$ ), $5^{\circ} \mathrm{C} \cdot \mathrm{min}^{-1}$ to $240^{\circ} \mathrm{C}(27 \mathrm{~min})$. After the column, the carrier gas was split 1:1 into a triple quadrupole mass spectrometer $\left(7000 \mathrm{~B}\right.$, Agilent Technologies; electron impact energy: $70 \mathrm{eV}$, transfer line: $250^{\circ} \mathrm{C}$, source: $230^{\circ} \mathrm{C}$, quadrupoles: $150^{\circ} \mathrm{C}$, He quench gas: $2.25 \mathrm{~mL} \cdot \mathrm{min}^{-1}, \mathrm{~N}_{2}$ collision gas: $1.5 \mathrm{~mL} \cdot \mathrm{min}^{-1}$, scan in $\mathrm{Q} 1 \mathrm{~m} / \mathrm{z}=33-300$ ) and an olfactory detector port (ODP 3, GERSTEL, Mülheim an der Ruhr, Germany, transfer line: $250^{\circ} \mathrm{C}$, mixing chamber: $150^{\circ} \mathrm{C}$, make up gas: $\mathrm{N}_{2}$ ). Alternatively, a DB-5MS column (Agilent Technologies, $30 \mathrm{~m} \times 0.25 \mathrm{~mm}$ i.d., $0.25 \mu \mathrm{m}$ film thickness) with analogous parameters was used. The volatile compounds were identified by comparison of the obtained Kováts retention indices (RI) and mass spectra with authentic standards and database entries (NIST 2011). RI were calculated from the retention times of n-alkanes (C8-C30, Sigma-Aldrich, Steinheim, Germany) by linear interpolation. The following standards, from Carl Roth, Acros Organics, AppliChem (Darmstadt, Germany) and Alfa Aesar (Karlsruhe, Germany), were chromatographed under identical conditions: hexane, octan-3-one, oct-1-en-3-one, oct-1-en-3-ol, acetic acid, benzaldehyde, (E)-oct-2-en-1-ol, butanoic acid, isovaleric acid, pentanoic acid and 2-phenylethanol.

\subsection{Statistics}

Analysis of variance (ANOVA) was calculated by the program OriginPro 9.0 (OriginLab Corporation, Northampton, MA, USA) with Fisher's least significant difference (LSD) test for comparing the mean values.

\section{Results and Discussion}

A. aegerita showed similar growth on wheat straw and all wheat straw containing substrates. On $100 \%$ cocoa shells the fungus showed only marginally growth around the inoculum which might be explained by an antimicrobial activity of the cocoa shells [16]. A second reason might be the inferior oxygen supply in less structured substrates compared to wheat straw, where the loose structure improves the availability of oxygen [17].

In a study by Zervakis et al. [9], different agro-waste materials were used for growing $A$. aegerita. They observed colonisation on the more structured substrates, such as peanut shells and sawdust, whereas on olive press cake no growth was observed. Nevertheless, certain mushrooms do grow on $100 \%$ cocoa shells, as shown by Bermùdez et al. [18] who cultivated Pleurotus ostreatus on this substrate.

In our case on $100 \%$ cacoa shells, no fruiting bodies could be harvested due to reduced growth of mycelia and absent primordia. In all wheat straw derived substrates, primordia formation started five weeks after inoculation. Interestingly, in wheat straw substrate supplemented with cocoa shells, the numbers of A. aegerita primordia exceeded those of all other substrates (Figure 1).

Fruiting bodies were harvested in a time span of 20 days starting five weeks after inoculation. The BE of fruiting body production varied from 23\% to 36\% between the different substrates (Figure 2). The BE on 100\% wheat straw (WS) of $33 \% \pm 11 \%$ was close to the yields obtained on wheat straw supplemented with cocoa shells (WS/CS; 31\% $\pm 5 \%$ ) and carrot mesh (WS/CM; 31\% $\pm 7 \%$ ). Supplementation with citrus pellets (WS/CP) reduced the yields to $23 \% \pm 5 \%$. The most efficient substrate mixture was wheat straw supplemented with black tea pomace. $\mathrm{BE}$ of $36 \% \pm 7 \%$ and $36 \% \pm 1 \%$ were obtained with wheat straw supplemented with $17 \%$ black tea pomace (WS/BT) and wheat straw with $45 \%$ black tea pomace (BT/WS), respectively. The BE of A. aegerita on $100 \%$ WS of $29.5 \%$ as reported by Schmithals and Schildbach [3] was comparable to the results of our study, while they could nearly double the BE (BE $58.0 \%$ ) by supplementation of wheat straw with $50 \%$ draff. In addition to the different substrate supplements they used, a harvest period of 22 weeks positively affected the BE [17]. In another study, the BE of three different $A$. aegerita strains cultivated on WS were, similar to our observations, between $25.5 \%$ and $31.0 \%$ [13]. However, two further strains of A. aegerita showed higher production yields of up to $49.8 \%$; it should be mentioned that these yields were obtained during two flushes [8]. On the 


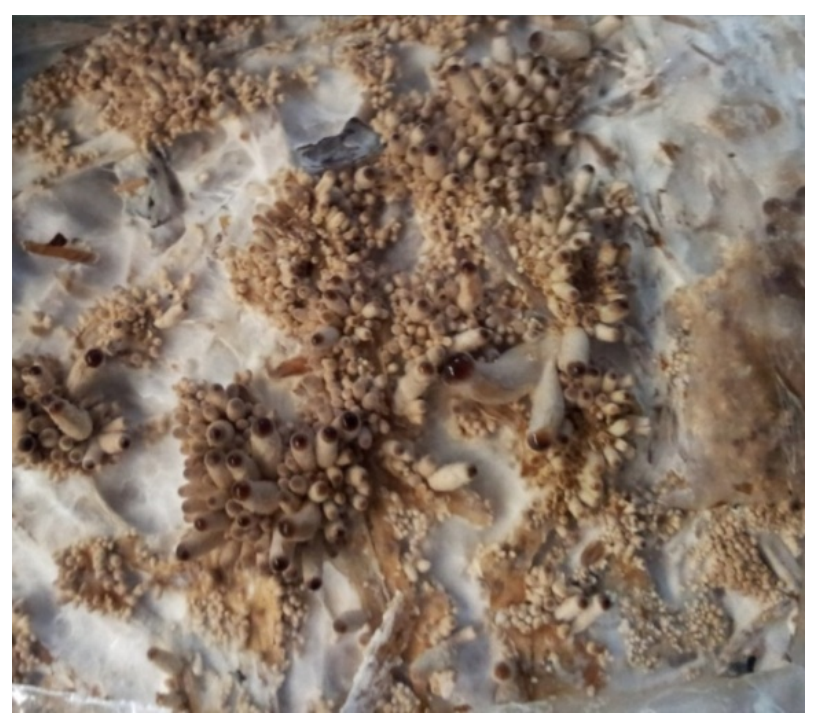

Figure 1. Primordia formation of $A$. aegerita cultivated on wheat straw supplemented with $17 \%$ cocoa shells.

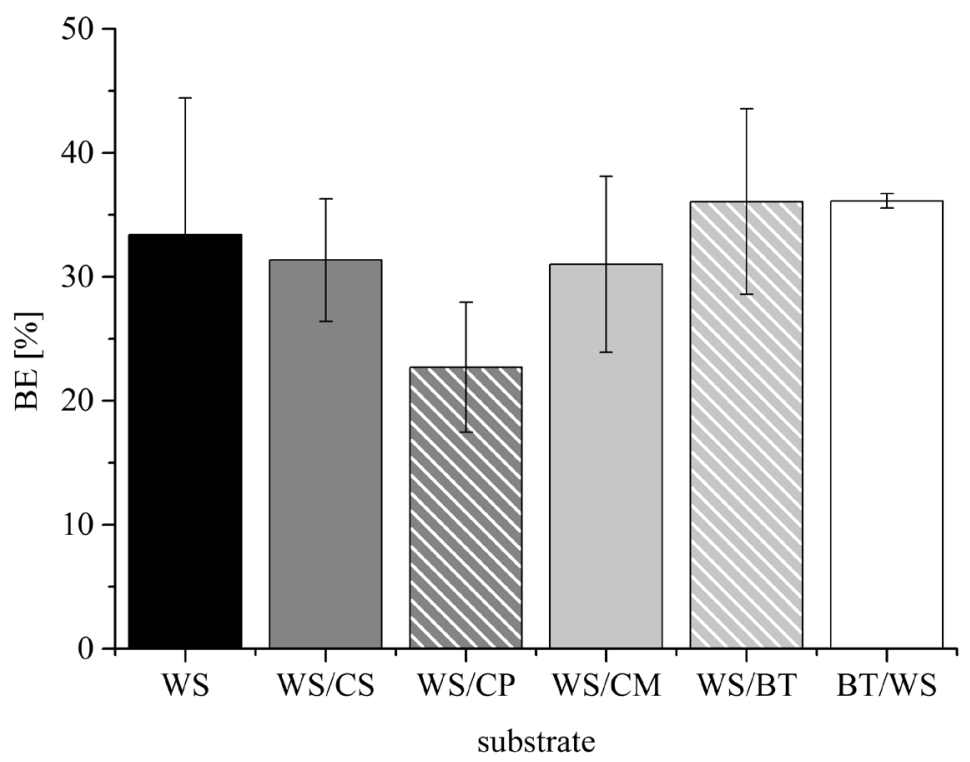

Figure 2. BE of $A$. aegerita grown on wheat straw (WS), WS and cocoa shells (WS/CS), WS and citrus pellets (WS/CP), WS and carrot mesh (WS/ CM), WS and $17 \%$ black tea pomace (WS/BT) and WS and $45 \%$ black tea pomace (BT/WS) with standard deviations.

other hand, also strains with lower BE have been tested as shown for strain 156 with a BE of only $10.1 \% \pm 2.4 \%$ [19].

Furthermore, the fruiting bodies were counted and grouped according to their size. The elevated primordia production observed on WS/CS (Figure 1) led to many small fruiting bodies (Figure 3). The largest fruiting bodies where obtained on WS/BT and BT/WS. The yields on wheat straw supplemented with black tea pomace were the highest though the number of fruiting bodies was lower compared to fruiting bodies grown on other substrates. Thus, wheat straw supplemented with black tea pomace seems to be favourable for industrial mushroom production. Beside the fruiting body yield, the aroma is the most important quality factor of mushrooms. Therefore, the effect of black tea pomace supplementation of the growth substrate on the aroma profile of $A$. aegerita was analysed by GC/MS/MS/O (Figure 4). 


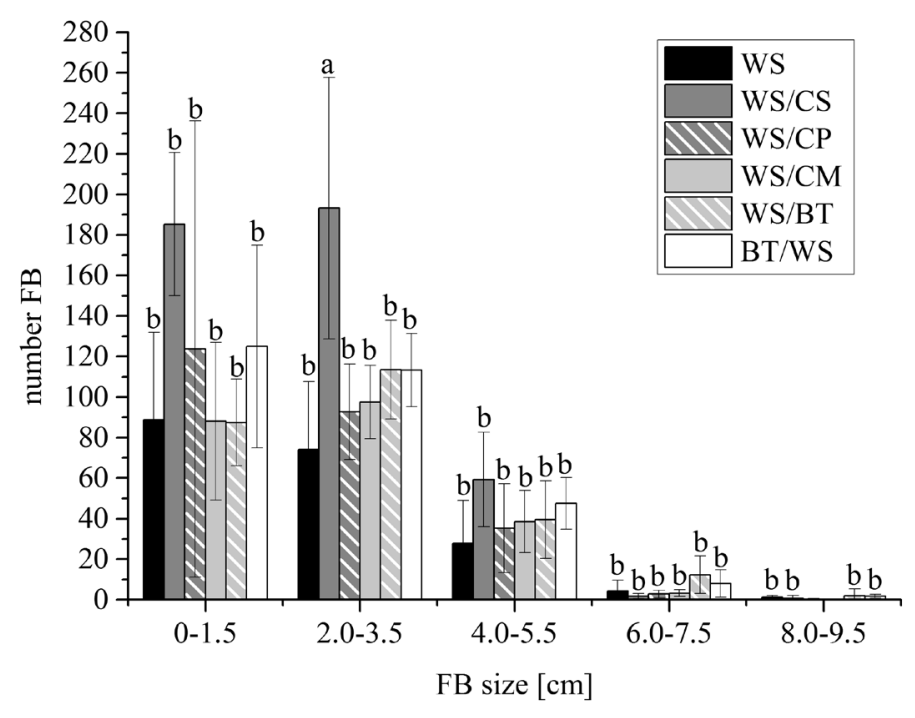

Figure 3. Number and size of fruiting bodies (FB) of $A$. aegerita grown on wheat straw (WS), WS and cocoa shells (WS/CS), WS and citrus pellets (WS/CP), WS and carrot mesh (WS/CM), WS and $17 \%$ black tea pomace (WS/BT) and WS and $45 \%$ black tea pomace (BT/WS) with standard deviation. Identical letters in each FB size category do not differ significantly (calculated by an ANOVA).

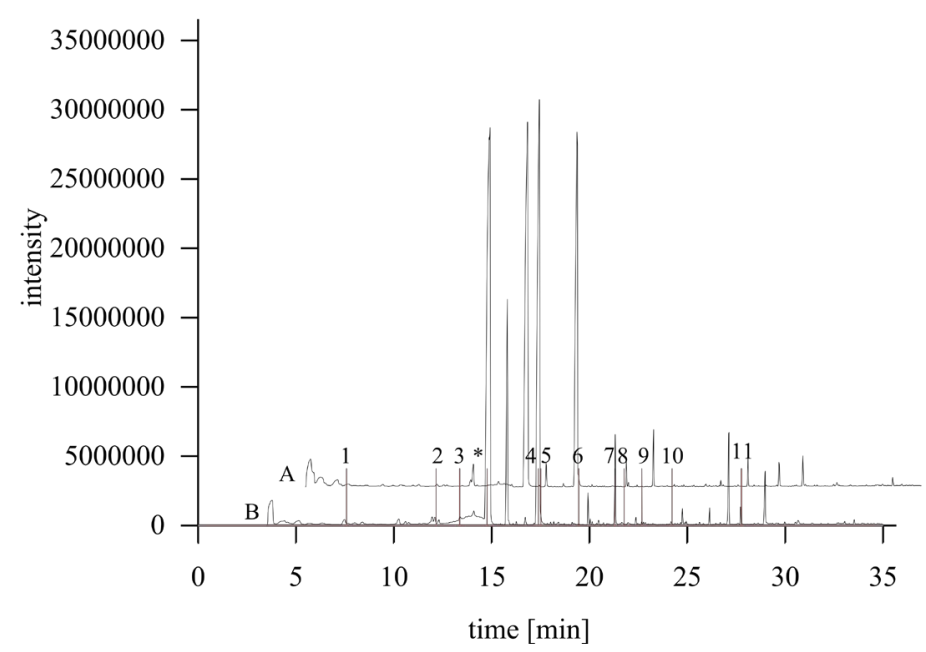

Figure 4. GC/MS/MS/O chromatograms of $A$. aegerita extracts; (A) A. aegerita grown on $100 \%$ wheat straw and (B) A. aegerita grown on $45 \%$ black tea; total ion count and ODP (olfactory detector port) signal (bars); *: internal standard.

The overall aroma profile of A. aegerita grown on BT/WS showed no significant differences compared to the cultivation on WS. Eleven aroma compounds were detected in both extracts (Table 1). Beside the typical mushroom flavours oct-1-en-3-one and oct-1-en-3-ol, a bloomy, rose like flavour was perceived, which was identified as 2-phenylethanol. Two green (cut grass) flavour compounds, hexane and octan-3-one, were identified as well. Additionally, acetic acid (vinegar flavour), benzaldehyde (almond flavour) and (E)-oct-2-en-1-ol (rancid odour) were identified. These compounds were previously detected by Rapior et al. [20] and in a preliminary study of our group [21]. In addition, three acids (butanoic acid, isovaleric acid and pentanoic acid) were tentatively identified, which have not been detected in A. aegerita before. While Rapior et al. [20] identified 22 volatiles in an organic extract of $A$. aegerita, only eleven compounds were perceived in the current study. A reason for this might be the different extraction methods. In this study, the extraction of volatile compounds was 
Table 1. Perceived odour impressions in extracts of $A$. aegerita by means of GC/MS/MS/O; fruiting bodies were grown on wheat straw (WS) and on wheat straw supplemented with black tea pomace (BT/WS); RI: Kováts retention index.

\begin{tabular}{|c|c|c|c|c|c|c|c|c|c|c|}
\hline \multirow[t]{2}{*}{ Peak } & \multirow[t]{2}{*}{$\begin{array}{c}\text { Odour } \\
\text { impression }\end{array}$} & \multirow[t]{2}{*}{ Compound } & \multicolumn{2}{|c|}{ RI WS } & \multicolumn{2}{|c|}{ RI BT/WS } & \multicolumn{2}{|c|}{ RI standard } & \multicolumn{2}{|c|}{ RI literature } \\
\hline & & & VF-WAXms & DB-5MS & VF-WAXms & DB-5MS & VF-WAXms & DB-5MS & Polar & Nonpolar \\
\hline 1 & Green & Hexanal & 1087 & 801 & 1087 & 801 & 1083 & 800 & 1088 [22] & 800 [22] \\
\hline 2 & Green & Octan-3-one & 1257 & 992 & 1257 & 992 & 1257 & 992 & 1240 [23] & 971 [23] \\
\hline 3 & Mushroom & Oct-1-en-3-one & 1301 & 984 & 1301 & 984 & 1301 & 984 & 1295 [24] & 982 [24] \\
\hline 4 & Mushroom & Oct-1-en-3-ol & 1456 & 988 & 1458 & 985 & 1452 & 986 & 1460 [24] & 992 [24] \\
\hline 5 & Vinegar & Acetic acid & 1458 & $<800$ & 1458 & $<800$ & 1455 & $<800$ & 1452 [25] & 600 [25] \\
\hline 6 & Almond & Benzaldehyde & 1523 & n.d. & 1523 & 968 & 1524 & 966 & 1521 [26] & 962 [27] \\
\hline 7 & Rancid & (E)-oct-2-en-1-ol & 1615 & 1073 & 1615 & 1073 & 1614 & 1074 & 1603 [28] & $1071[23$ \\
\hline 8 & Cheese & Butanoic acid & 1635 & n.d. & 1632 & n.d. & 1631 & 807 & 1640 [29] & 863 [29] \\
\hline 9 & Cheese & Isovaleric acid & 1675 & n.d. & 1674 & n.d. & 1675 & 866 & 1660 [30] & 840 [30] \\
\hline 10 & Cheese & Pentanoic acid & 1742 & n.d. & 1742 & n.d. & 1740 & 906 & 1747 [29] & 904 [31] \\
\hline 11 & Rose & 2-Phenylethanol & 2010 & 1116 & 2010 & 1116 & 2011 & 1116 & 1916 [25] & $1108[25]$ \\
\hline
\end{tabular}

The compounds were detected in A. aegerita extracts from fruiting bodies grown on WS as well as on BT/WS. Furthermore, volatiles were confirmed by comparing KI with literature data and sensory evaluation by olfactometry analysis; n.d.: no distinct MS spectrum on DB-5MS column.

performed three times, each step lasting approximately five minutes, whereas Rapior et al. macerated the fruiting bodies for seven days in the organic solvent dichloromethane.

\section{Conclusion}

Cultivation of A. aegerita on different substrates based on wheat straw supplemented with different residual materials from the food industry was possible. In addition to the exploitation of these waste materials, the yields of fruiting bodies could be increased by supplementing wheat straw with black tea pomace, a by-product of the beverage industry. The thus produced mushrooms should be as marketable as the ones produced on wheat straw, as a comparison of the aroma profiles of mushrooms grown on both substrates showed no significant differences. Eleven aroma compounds were detected in the extracts of the fruiting bodies of A. aegerita: hexane, octan-3-one, oct-1-en-3-one, oct-1-en-3-ol, acetic acid, benzaldehyde, $(E)$-oct-2-en-1-ol, butanoic acid, isovaleric acid, pentanoic acid and 2-phenylethanol.

\section{Acknowledgements}

The authors would like to thank Prof. Dr. D. Steffens for providing the climate chamber used in this study. Support of Plantextrakt (Bad Kissingen, Germany) for providing black tea pomace and Pilzzucht Hesse for providing autoclavable polyethylene culture bags is gratefully acknowledged. The study was financially supported by the excellence initiative of the Hessian Ministry of Science and Art which encompasses a generous grant for the LOEWE focus "integrative fungal research". The authors also would like to thank the DFG and the State of Hesse for funding the GC/MS/MS/O system (INST 162/381-1 FUGG).

\section{References}

[1] Rühl, M. and Kües, U. (2007) Mushroom Production. In: Kües, U., Ed., Wood Production, Food Technology, and Biotechnological Impacts, Universitätsverlag Göttingen, 555-586.

[2] Diyabalanagea, T., Mulabagala, V., Millsb, G., DeWittc, D.L. and Naira, M.G. (2008) Health-Beneficial Qualities of the Edible Mushroom, Agrocybe aegerita. Food Chemistry, 108, 97-102.

[3] Uhart, M., Piscera, J.M. and Albertó, E. (2008) Utilization of New Naturally Occurring Strains and Supplementation to Improve the Biological Efficiency of the Edible Mushroom Agrocybe cylindracea. Journal of Industrial Microbiology \& Biotechnology, 35, 595-602. http://dx.doi.org/10.1007/s10295-008-0321-1

[4] Ngai, P.H.K., Zhao, Z. and Ng, T.B. (2005) Agrocybin, an Antifungal Peptide from the Edible Mushroom Agrocybe 
cylindracea. Peptides, 26, 191-196. http://dx.doi.org/10.1016/j.peptides.2004.09.011

[5] Zhao, C., Sun, H., Tong, X. and Qi, Y. (2003) Anantitumourlectin from the Edible Mushroom Agrocybe aegerita. Biochemical Journal, 374, 321-327. http://dx.doi.org/10.1042/BJ20030300

[6] Venkateshwarlu, G., Chandravadana, M.V. and Tewari, R.P. (1999) Volatile Flavour Components of Some Edible Mushrooms (Basidiomycetes). Flavour and Fragrance Journal, 14, 191-194. http://dx.doi.org/10.1002/(SICI)1099-1026(199905/06)14:3<191::AID-FFJ810>3.0.CO;2-7

[7] Hadar, Y. and Dosoretz, C.G. (1991) Mushroom Mycelium as a Potential Source of Food Flavour. Trends in Food Science and Technology, 2, 214-218. http://dx.doi.org/10.1016/0924-2244(91)90693-D

[8] Philippoussis, A., Zervakis, G. and Diamantopoulou, P. (2001) Bioconversion of Agricultural Lignocellulosic Wastes through the Cultivation of the Edible Mushrooms Agrocybe aegerita, Volvariellavolvacea and Pleurotus spp. World Journal of Microbiology and Biotechnology, 17, 191-200. http://dx.doi.org/10.1023/A:1016685530312

[9] Zervakis, G., Philippoussis, A., Ioannidou, S. and Diamantopoulou, P. (2001) Mycelium Growth Kinetics and Optimal Temperature Conditions for the Cultivation of Edible Mushroom Species on Lignocellulosic Substrates. Folia Microbiologica, 46, 231-234. http://dx.doi.org/10.1007/BF02818539

[10] Isikhuemhen, O.S., Mikiashvili, N.A. and Kelkar, V. (2009) Application of Solid Waste from Anaerobic Digestion of Poultry Litter in Agrocybe aegerita Cultivation: Mushroom Production, Lignocellulolytic Enzymes Activity and Substrate Utilization. Biodegradation, 20, 351-361. http://dx.doi.org/10.1007/s10532-008-9226-y

[11] Nicolini, L., von Hunolstein, C. and Carilli, A. (1987) Solid State Fermentation of Orange Peel and Grape Stalks by Pleurotus ostreatus, Agrocybe aegerita, and Armillariellamellea. Applied Microbiology and Biotechnology, 26, 95-98. http://dx.doi.org/10.1007/BF00282155

[12] Sánchez, C. (2010) Cultivation of Pleurotus ostreatus and Other Edible Mushrooms. Applied Microbiology and Biotechnology, 85, 1321-1337. http://dx.doi.org/10.1007/s00253-009-2343-7

[13] Uhart, M., Piscera, J.M. and Albertó, E. (2008) Utilization of the New Naturally Occurring Strains and Supplementation of Improve the Biological Efficiency of the Edible Mushroom Agrocybe cylindracea. Journal of Industrial Microbiology \& Biotechnology, 35, 595-602. http://dx.doi.org/10.1007/s10295-008-0321-1

[14] Pfaltzgraff, L.A., De bruyn, M., Cooper, E.C., Budarin, V. and Clark, J.H. (2013) Food Waste Biomass: A Resource for High-Value Chemicals. Green Chemistry, 15, 307-314. http://dx.doi.org/10.1039/C2GC36978H

[15] Sánchez, C. (2004) Modern Aspects of Mushroom Culture Technology. Applied Microbiology and Biotechnology, 64, 756-762. http://dx.doi.org/10.1007/s00253-004-1569-7

[16] Nsor-Atindana, J., Zhong, F., Mothibe, K.J., Bangoura, M.L. and Lagnika, C. (2012) Quantification of Total Polyphenolic Content and Antimicrobial Activity of Cocoa (Theobroma cacao L.) Bean Shells. Pakistan Journal of Nutrition, 11, 574-579.

[17] Schmithals, K. and Schildbach, R. (1992) Der Anbau des südlichen Schüpplings (Agrocybe aegerita) auf Schüttsubstraten mit Trebern. Der Champignon, 3, 78-82.

[18] Bermúdez, R.C., García, N., Gross, P. and Serrano, M. (2001) Cultivation of Pleurotus on Agricultural Substrates in Cuba. Micología Aplicada International, 13, 25-29.

[19] Isikhuemhen, O.S., Mikiashvili, N.A. and Kelkar, V. (2009) Application of Solid Waste from Anaerobic Digestion of Poultry Litter in Agrocybe aegerita Cultivation: Mushroom Production, Lignocellulolytic Enzymes Activity and Substrate Utilization. Biodegradation, 20, 351-361. http://dx.doi.org/10.1007/s10532-008-9226-y

[20] Rapior, S., Breheret, S., Talou, T., Pélissier, Y., Milhau, M. and Bessière, J.M. (1998) Volatile Components of Fresh Agrocybe aegerita and Tricholoma sulfureum. Cryptogamie Mycologie, 19, 15-23.

[21] Kleofas, V., Heuger, A., Fraatz, M.A., Rühl, M. and Zorn, H. (2014) Aroma Profile of the Mushroom Agrocybe aegerita. Proceedings of the 10th Wartburg Symposium on Flavour Chemistry \& Biology, in press.

[22] Wang, Y., Finn, C. and Qian, M.C. (2005) Impact of Growing Environment on Chickasaw Blackberry (Rubus L.) Aroma Evaluated by Gas Chromatography Olfactometry Dilution Analysis. Journal of Agricultural and Food Chemistry, 53, 3563-3571. http://dx.doi.org/10.1021/jf048102m

[23] Cho, I.H., Kim, S.Y., Choi, H.-K. and Kim, Y.-S. (2006) Characterization of Aroma-Active Compounds in Raw and Cooked Pine-Mushrooms (Tricholoma matsutake Sing.). Journal of Agricultural and Food Chemistry, 54, 6332-6335. http://dx.doi.org/10.1021/jf060824l

[24] Seo, W.H. and Baek, H.H. (2009) Characteristic Aroma-Active Compounds of Korean Perilla (Perilla frutescens Britton) Leaf. Journal of Agricultural and Food Chemistry, 57, 11537-11542. http://dx.doi.org/10.1021/jf902669d

[25] San-Juan, F., Pet'ka, J., Cacho, J., Ferreira, V. and Escudero, A. (2010) Producing Headspace Extracts for the Gas Chromatography-Olfactometric Evaluation of Wine Aroma. Food Chemistry, 123, 188-195. http://dx.doi.org/10.1016/j.foodchem.2010.03.129 
[26] Alasalvar, C., Shahidi, F. and Cadwallader, K.R. (2003) Comparison of Natural and Roasted Turkish Tombul Hazelnut (Corylus avellana L.) Volatiles and Flavor by DHA/GC/MS and Descriptive Sensory Analysis. Journal of Agricultural and Food Chemistry, 51, 5067-5072. http://dx.doi.org/10.1021/jf0300846

[27] Jordán, M.J., Margaría, C.A., Shaw, P.E. and Goodner, K.L. (2003) Volatile Components and Aroma Active Compounds in Aqueous Essence and Fresh Pink Guava Fruit Puree (Psidium guajava L.) by GC-MS and Multidimensional GC/GC-O. Journal of Agricultural and Food Chemistry, 51, 1421-1426. http://dx.doi.org/10.1021/jf020765l

[28] Chandravadana, M.V., Vekateshwarlu, G., BujjiBabu, C.S., Roy, T.K., Shivashankara, K.S., Pandey, M., Tewari, R.P. and Selvaraj, Y. (2005) Volatile Flavour Components of Dry Milky Mushrooms (Calocybe indica). Flavour and Fragrance Journal, 20, 715-717. http://dx.doi.org/10.1002/ffj.1653

[29] Lee, S.M., Seo, B.C. and Kim, Y.S. (2006) Volatile Compounds in Fermented and Acid-Hydrolyzed Soy Sauces. Journal of Food Science, 71, C146-C156. http://dx.doi.org/10.1111/j.1365-2621.2006.tb15610.x

[30] Ong, P.K.C. and Acree, T.E. (1998) Gas Chromatography/Olfactory Analysis of Lychee (Litchi chinesis Sonn.). Journal of Agricultural and Food Chemistry, 46, 2282-2286. http://dx.doi.org/10.1021/jf9801318

[31] Machielsa, D., van Ruthb, S.M., Posthumusc, M.A. and Istassea, L. (2003) Gas Chromatography-Olfactometry Analysis of the Volatile Compounds of Two Commercial Irish Beef Meats. Talanta, 60, 755-764. http://dx.doi.org/10.1016/S0039-9140(03)00133-4 